\title{
Effects of group sexual counseling on the traditional perceptions and attitudes of Iranian pregnant
} \section{women}

\section{Ali Navidian'}

Shahindokht Navabi Rigi

Parvin Soltani ${ }^{2}$

'Department of Counseling, Pregnancy Health Research Center, Zahedan University of Medical Sciences, Zahedan, Iran; ${ }^{2}$ Department of Midwifery, Nursing and Midwifery School, Zahedan University of Medical Sciences, Zahedan, Iran
Correspondence: Parvin Soltani Department of Midwifery, Nursing and Midwifery School, Zahedan University of Medical Sciences, Mashahir Square, PO Box 98139-1379, Zahedan, Iran

Tel +985433442482

Fax +98543344 248I

Email p_soltani.ac88@yahoo.com
This article was published in the following Dove Press journal:

International Journal of Women's Health

13 June 2016

Number of times this article has been viewed

Background: Marital relationships may fluctuate due to physical and psychological changes during pregnancy. This study aimed to investigate the effect of group sexual counseling on the traditional perceptions and attitudes of pregnant women.

Methods: This was a quasiexperimental intervention study. Among the pregnant women who were referred to health care centers in Zahedan, Iran, in 2015 for routine care during pregnancy, 100 individuals were chosen and randomly categorized into two groups: intervention $(n=50)$ and control $(n=50)$. Variables were the participant's attitudes and beliefs on sexual activity during pregnancy. The data were collected during pregnancy using the Sexual Activities and Attitudes Questionnaire. The questionnaire was completed before and 6 weeks after five sessions of group sexual counseling. Data were analyzed using SPSS software (Version 20) with descriptive and analytical statistics.

Results: The mean of score changes for sexual attitudes and traditional perceptions in the intervention group was significantly higher than that in the control group $(P<0.0001)$. Analysis of covariance also showed that the mean score of the participant's traditional perceptions and sexual attitudes in both groups was significantly different after the group sexual counseling.

Discussion: Due to the positive effect of group sexual counseling on improving the attitudes of pregnant women about sexual issues and reframing the traditional perceptions over sexual activities during pregnancy, it is recommended that this educational intervention should be integrated into counseling and prenatal care for pregnant women.

Keywords: group sexual counseling, belief, attitude, pregnancy

\section{Background}

Pregnancy is a unique period in women's lives and an important part of the couple's experience. ${ }^{1}$ This transition period affects the sexual orientation and sexual life of couples through creating physical, emotional, and psychological changes, along with sociocultural factors ${ }^{2,3}$ and religious beliefs. ${ }^{2-4}$ Marital and sexual relations during pregnancy change considerably as a result of several physical and psychological changes. In other words, during transition from the role of a spouse to that of a parent, the relationship between a couple changes. ${ }^{5}$ The quality of their relationship during pregnancy is largely influenced by their sexual relations and their set of specific beliefs; this is a global issue. ${ }^{6}$

Sexual activity during pregnancy is influenced by several factors including hormonal changes, such as increased levels of estrogen, progesterone, and prolactin, which may reduce the sexual desire and motivation due to nausea, vomiting, breast tenderness, weight gain, anxiety, fatigue, etc. ${ }^{7-9}$ 
Many studies have shown that decreased sexual function occurs normally during pregnancy, especially during the first trimester, due to fatigue, nausea, vomiting, emotional changes, breast tenderness, intensified anxiety, and fear of abortion. ${ }^{10-12}$ During the second trimester, women have more energy, sexual feeling, sexual desire, and vaginal lubrication that decreases the physical discomfort and previous concerns. It is probable that, during this period, pregnant women may reach orgasm for the first time or find it easier than before the pregnancy, ${ }^{11}$ as, at this stage, pelvic blood flow increases, and it is believed that this leads to increased sexual desire and satisfaction. However, studies do not support this hypothesis, and it has been shown that a linear decrease in sexual desire and satisfaction occurs with the progress of pregnancy. ${ }^{13}$ During the third trimester of pregnancy, physical pain, dyspnea, weight gain, back pain, and other obstacles again make sexual activities more difficult. ${ }^{11,14}$

Most sexual problems that occur during pregnancy are caused by wrong beliefs, misconceptions, and a lack of proper understanding of the physical and emotional changes at this time. ${ }^{12,15}$ In addition, cultural, social, ethnic, and religious issues, ${ }^{16}$ the role of the woman's identity, the reality of motherhood, spouses' attitude to pregnancy, women's beliefs about sexual desire, and misconceptions about the dangers of sexual intercourse in this period cause changes in sexual behavior. ${ }^{17}$

There are many beliefs and superstitions associated with sexual activity among women. These go beyond national borders without ethnic or racial division; in other words, this is a global phenomenon. ${ }^{18}$ Numerous studies have been conducted on the factors affecting female sexual function during pregnancy in some countries such as Cameroon, ${ }^{17}$ Lithuania, ${ }^{2}$ Nigeria, ${ }^{10}$ People's Republic of China, ${ }^{19}$ Turkey, ${ }^{20}$ Pakistan, ${ }^{21}$ and Thailand. ${ }^{22}$ Similar studies have been conducted in some parts of Iran including Tehran, ${ }^{23}$ Tabriz, ${ }^{24}$ Golestan, ${ }^{18}$ and Hamedan. ${ }^{6}$

Reported reasons for avoiding or reducing sexual activity during pregnancy, in the view of women, are a fear of damage to the fetus, infections, looking and being aware of their fetus, fear of abortion, and premature rupture of fetal membranes. Traditional perceptions have a significant impact on a person's sexual reaction and, consequently, on the couple's relationship, and may jeopardize the health of a couple's marital life. ${ }^{18,20}$ Undoubtedly, couples' relations during pregnancy and the quality of these relations are largely influenced by their normal sexual relations and set of specific beliefs. Since a couple's attitude toward the physical and emotional changes of pregnancy impacts their relations, the lack of a proper understanding of these changes, plus inadequate information regarding sexual relations during this period, may result in relational problems. This, finally, impacts on their emotional state and sincerity within the relationship; especially in women, it creates dissatisfaction, anxiety, and a lack of self-confidence. ${ }^{6}$ Some sexual problems during pregnancy are caused by a lack of knowledge and experience, sexual misconceptions, or the couple's inability to state their own sexual preferences. ${ }^{21}$

Studies have shown that most Iranian couples are not aware of the quality of sexual relations during pregnancy, and there has always been a need for training and consultation concerning sexual issues at this time. ${ }^{22}$ Therefore, by providing sexual counseling to pregnant women, wrong beliefs, attitudes, and information about sexual activities should be rejected, natural changes occurring in pregnancy should be taught, and appropriate sexual behavior should be individually recommended. Finally, attention to the couple's sexual health, recognizing their concerns, helping to resolve these concerns, and improving their sexual function should be among the main topics of prenatal care. ${ }^{23}$

In Iran, despite an effective and efficient primary health care system, the issue of sexual counseling during pregnancy, especially in some parts of the country, has not been fully assessed, and there are gaps in this regard. Thus, there is a need for training according to the cultural, social, and religious context of women in these areas of the country. Information about the beliefs and attitudes toward sex during pregnancy, in addition to identifying the improper sexual beliefs of women, can help health care workers in correcting misconceptions by counseling pregnant women. This can create more positive attitudes toward sex during pregnancy and improve a couple's sexual relations through stress reduction. Therefore, the present study aimed to determine the effect of group sexual counseling on the traditional perceptions and attitudes of pregnant women.

\section{Methods}

This was a quasiexperimental intervention study. Among the pregnant women who were referred to health care centers in Zahedan city, Iran, in 2015 for routine care during pregnancy, 100 individuals were randomly categorized into two groups intervention $(n=50)$ and control $(n=50)$. The women were allocated into two groups on a weekly basis, so they would not have contact with each other. Inclusion criteria comprised healthy pregnant women aged 18-39 years with a gestational age of 15-28 weeks based on last menstrual period or sonography, having health records in the health center, living 
with a husband, and also undergoing a current pregnancy without complications such as vaginal bleeding, placenta previa, cervical cerclage, multiple pregnancies, pregnancy with assisted reproduction techniques, threatened abortion, and chronic medical conditions such as hypertension and diabetes. A history of recent or repeated abortions, addiction, and history of sexual disorder or any other untreated psychiatric disorders before pregnancy, polygamy, and use of psychiatric drugs, such as antidepressants, were among the exclusion criteria. The dependent variables measured in the current study were traditional perceptions and attitudes toward sexual activity during pregnancy. For this purpose, a three-part questionnaire was used.

\section{Instruments}

The instrument was a researcher-assembled questionnaire consisting of three parts. The first part was related to demographic and pregnancy characteristics with some questions concerning age, education level, occupation, birth order, and gestational age. The second part dealt with sexual beliefs in pregnancy (Figure S1). The third part was concerned with the woman's attitude toward sexual activity during pregnancy (Figure S2). The questionnaire of sexual beliefs of the pregnancy period was derived from the study by Sossah ${ }^{17}$ and Riazi et al, ${ }^{6}$ which was modified and completed after reading related books and resources. To confirm the content and face validity of the questionnaire, it was offered to nine professors and experts in Obstetrics and Gynecology and Psychology, and their corrective comments were addressed and applied. Ultimately, it was designed in the form of a 12-item questionnaire. The questionnaire was completed by 30 pregnant women who met the inclusion criteria, and 10 days later, it was again completed by the same group. Pearson's correlation coefficient between the two occasions of measuring was $r=0.89$. Furthermore, the internal consistency of the questionnaire was assessed by using Cronbach's $\alpha$ method, as 0.89 . The 12 -item sexual beliefs questionnaire was scored as yes/no and 0 and 1 . Therefore, the range of obtained scores varied between a minimum of 0 and a maximum of 12 . Higher scores indicated more wrong beliefs about sexual activity during pregnancy.

The sexual attitude questionnaire was derived from the study by Bayrami et al, ${ }^{24}$ Merghati Khoei et al, ${ }^{25}$ and Riazi et al. ${ }^{6}$ The questionnaire was completed through library studies and was given to seven specialists and faculty members of Nursing and Midwifery and Obstetricians to comment and determine its face value and content validity. The final 12-item questionnaire was completed by
30 pregnant women who met the inclusion criteria; 10 days later, it was again completed by the same group. Pearson's correlation coefficient between the two measurement periods was $r=0.80$. Moreover, the internal consistency of the questionnaire was determined, by using the Cronbach's $\alpha$ method, as 0.73 . The responses of the attitude questionnaire were set based on the five-point Likert scale, from the point of "agree" to "disagree". Each option had a score between 0 and 4 . The total score of each person was a minimum 0 and a maximum of 48. Higher scores indicated a more correct attitude toward sexual activity during pregnancy.

\section{Intervention}

Group sexual counseling was designed and accomplished in the form of a psychological training package and as a visualwritten guide. In addition, a compact disc of sexual training, which was approved by the Ministry of Health, was used selectively in the meetings. The educational content of the group sexual counseling was prepared from related articles, books, journals, and scientific research. The determined educational content was offered during five sessions of 1-1.5 hours during a 2 -week period at the already coordinated times when the women visited the health centers. The meetings included lectures using PowerPoint presentations, movies and photos, and question \& answer. Among the most important topics discussed were a short review of the anatomy and physiology of male and female reproductive organs, their changes during pregnancy, mental changes at different stages of pregnancy, the sexual response cycle of males and females, changes of sexual response cycle during pregnancy, recall of common sexual misconceptions and challenging them through group discussion, determining attitudes toward sexual activity during pregnancy, a review of sexual disorders especially during pregnancy, providing facts on the importance of satisfying sexual needs, the role of sexual relations in the context of the overall relationship and the dimensions of quality of the marital relationship, and presenting appropriate and safe positions for sexual activity during pregnancy.

After obtaining ethical permission from the Regional Ethical Review Board of Zahedan University of Medical Sciences (approval number: IR.ZAUMS.REC.1394.89) to conduct this study, the health centers were randomly selected from among the five regions of the city. Then, according to the time schedule, the researcher visited each clinic and selected eligible subjects from the pregnant women referred to the center. The selected women were randomly assigned into two groups - intervention and control. At first, the questionnaires 
were completed by both groups (pretest). Then, in the intervention group, the required coordination for holding group sexual counseling sessions was performed. After reaching an adequate number of subjects, the intervention was conducted in the form of groups of five to ten people by the researcher. Again, 6 weeks after the last session of group sexual consultation, the questionnaires were completed by both groups (posttest). The control group received no intervention, just routine prenatal care. Obtaining written informed consent, confidentiality of personal and sexual information, describing the objectives of the study, and describing the research method were the most important ethical considerations in this study. All participants provided written informed consent.

\section{Statistical analysis}

Data analysis was performed using SPSS 20 software (IBM Corporation, Armonk, NY, USA). The frequency, percentage, mean, standard deviation, minimum, and maximum were determined by using descriptive statistics. Then a paired $t$-test was used for comparison of the mean scores before and after in both groups. An independent $t$-test was used for comparison of the mean scores between the two groups of intervention and control. The chi-square test was employed for comparison of the qualitative variables in the two groups. Finally, analysis of covariance (ANCOVA) was used to determine the effectiveness of group sexual counseling through the control of some confounding variables. The significance level in this study was considered as 0.05 .

\section{Results}

The results of the Shapiro-Wilk test showed that the data related to the considered variables were normally distributed, so parametric tests were used. The mean age of the intervention and control groups was $27.32 \pm 5.55$ and $26.54 \pm 5.22$ years, respectively (with a range of 18-39 years in both groups). The independent $t$-test showed that the mean age of the two groups was similar $(P=0.4)$. Housewives made up $90 \%$ of the intervention group and $84 \%$ of the control group. The majority of the cases in the intervention (64\%) and control $(62 \%)$ groups were high school graduates and above. Fiftyfour percent of the intervention group and $70 \%$ of the control group were Shia. The mean duration of marriage for the two groups was $6.28 \pm 5.38$ and $6.14 \pm 4.61$ years, respectively (with a range of 1-18 years in both groups).

The minimum and maximum age of the spouses were 20 and 52 years and 21 and 58 years, respectively, in the intervention and control groups. The mean age of the spouses in the intervention and control groups was $30.92 \pm 6.35$ and
$31.04 \pm 6.31$ years, respectively. The majority of spouses in both groups (66\% in the intervention group and $62 \%$ in the control group) were high school graduates and above. Furthermore, the mean and standard deviation of the number of pregnancies in the intervention and control groups were $2.22 \pm 12.17$ (with a range of one to five pregnancies) and $2.18 \pm 1.20$ (with a range of one to six pregnancies), respectively. The mean gestational age of the two groups was $19.72 \pm 4.0$ and $21.42 \pm 3.88$ weeks, respectively (with a range of 15-28 weeks in both groups). There was no significant difference between the two groups in terms of these aforementioned demographic variables (Table 1).

The mean and standard deviation of the score of the pregnant women's traditional perceptions before sexual counseling were $4.76 \pm 2.59$ and $4.76 \pm 2.70$ in the intervention and control groups, respectively; this was $1.34 \pm 1.09$ and $4.52 \pm 2.54$, respectively, at posttest (Table 2 ). The mean change in the score of traditional perceptions of pregnant women in the intervention group $(-3.42 \pm 2.08)$ was significantly different from that in the control group $(-0.24 \pm 1.02, P<0.0001)$. The results showed that the highest shift posttest occurred in the traditional perceptions, including damage to the fetus, maternal infection, and annoying genital pains. The lowest was in relation to the rupture of the hymen in the case of a female fetus and an increase of sexual perversion after birth in children.

The results of ANCOVA tests showed that the mean score of the traditional perceptions of pregnant women in the intervention group was significantly lower than in the control group at posttest by the covariance of some variables, such as age of man and woman, education level of man and woman, marriage duration, religion, and job; this indicated that sexual counseling led to a decrease in the traditional perceptions of pregnant women $(P<0.0001)$.

As Table 3 shows, counseling affected the mean and standard deviation of the score of sexual attitude in pregnancy, such that the mean score before sexual counseling in the intervention and control groups was 23.96 \pm 8.0 and 23.62 \pm 7.03 , while after intervention, it was $35.62 \pm 6.01$ and 23.20 \pm 5.69 , respectively. The mean change in the score of sexual attitude in the intervention group (11.66 \pm 5.10$)$ was significantly greater than in the control group $(-0.42 \pm 3.03, P=0.0001)$. The findings indicated that the most striking shifts for unfavorable attitudes were concerned with reduced sexual activity due to physical changes, lack of access to sexual pleasure without intercourse, and low sexual attractiveness. The least changes were related to a decrease in attention from the husband during pregnancy and having sex with fear of aggression from him. 
Table I Demographic characteristics of intervention and control groups

\begin{tabular}{|c|c|c|c|}
\hline Characteristics & Intervention (mean $\pm \mathbf{S D}$ ) & Control (mean $\pm \mathbf{S D})$ & $P$-value \\
\hline Age, years & $27.32 \pm 5.55$ & $26.54 \pm 5.22$ & 0.4 \\
\hline Husband's age, years & $30.92 \pm 6.35$ & $31.04 \pm 6.31$ & 0.9 \\
\hline Duration of marriage, years & $6.14 \pm 4.61$ & $6.28 \pm 5.38$ & 0.8 \\
\hline Number of pregnancies & $2.22 \pm 1.21$ & $2.18 \pm 1.20$ & 0.8 \\
\hline \multirow[t]{2}{*}{ Gestational age, weeks } & $19.72 \pm 4.07$ & $21.42 \pm 3.88$ & 0.3 \\
\hline & Intervention N (\%) & Control N (\%) & \\
\hline Women's education & & & 0.6 \\
\hline Primary school & $8(16 \%)$ & $7(14 \%)$ & \\
\hline Secondary school & $10(20 \%)$ & $9(18 \%)$ & \\
\hline High school & $0(0 \%)$ & $3(6 \%)$ & \\
\hline Diploma or above & $32(64 \%)$ & 31 (62\%) & \\
\hline Educational level & & & 0.1 \\
\hline Primary school & 7 (14\%) & $3(6 \%)$ & \\
\hline Secondary school & $10(20 \%)$ & 14 (28\%) & \\
\hline High school & $0(0 \%)$ & $2(4 \%)$ & \\
\hline Diploma or above & $33(66 \%)$ & $31(62 \%)$ & \\
\hline Occupation & & & 0.3 \\
\hline Employed & $5(10 \%)$ & $8(16 \%)$ & \\
\hline Housewife & $45(90 \%)$ & $42(84 \%)$ & \\
\hline Religion & & & 0.6 \\
\hline Shia & 27 (54\%) & $35(70 \%)$ & \\
\hline Sunni & $23(46 \%)$ & $15(30 \%)$ & \\
\hline
\end{tabular}

Abbreviation: SD, standard deviation.

The ANCOVA tests showed that the mean score of sexual attitude in pregnancy in the intervention group posttest was significantly higher than in the control group by the covariance of age of man and woman, education level of man and woman, marriage duration, religion, and job. This indicated that sexual counseling improved the participant's attitudes about sexual activity during pregnancy $(P<0.0001)$.

It was also shown that the main sources for receiving information on sexual issues were experimental (during marital relations) and through friends; only $9.92 \%$ of the individuals indicated that they had received information through health center staff.

\section{Discussion}

This study was conducted to determine the effect of group sexual counseling on the traditional perceptions and attitudes of pregnant women toward sexual issues during pregnancy.
The results showed that sexual counseling could lead to a change in traditional perceptions and a proper attitude toward sexual issues during pregnancy. The mean score of traditional perceptions in the intervention group after sexual counseling was meaningfully lower than in the control group. The ANCOVA test indicated that sexual counseling caused a decrease in traditional perceptions, especially in sexual activity during pregnancy; the maximum score change was related to traditional perceptions of damage to the fetus, maternal infections, and annoying hymen pains, and the least change was related to tearing the hymen in a female fetus and increased sexual perversion in children. In line with these findings, studies by Riazi et $\mathrm{al}^{6}$ indicated that traditional perceptions such as fear of damage to the fetus, infections, stomach ache, and unpleasant feelings toward sexual activity during pregnancy had decreased among women who attended sex education classes. The study by Shojae et $\mathrm{al}^{26}$ showed that an awareness of changes

Table 2 Comparison of the mean and standard deviation (SD) of the score for traditional perceptions in pregnant women in the intervention and control groups before and after sexual counseling

\begin{tabular}{lllc}
\hline Group & $\begin{array}{l}\text { Before counseling } \\
\text { (mean } \pm \text { SD) }\end{array}$ & $\begin{array}{l}\text { After counseling } \\
\text { (mean } \pm \text { SD) }\end{array}$ & $\begin{array}{l}\text { Changes } \\
\text { (mean } \pm \text { SD) }\end{array}$ \\
\hline Intervention & $4.76 \pm 2.59$ & $1.34 \pm 1.09$ & $3.42 \pm 2.08$ \\
Control & $4.76 \pm 2.70$ & $4.52 \pm 2.54$ & $0.24 \pm 1.02$ \\
Student's t-test & $P=0.9$ & $P=0.0001$ & $P=0.0001$ \\
\hline
\end{tabular}

Abbreviation: NA, not applicable. 
Table 3 Comparison of the mean and standard deviation (SD) of the score for sexual attitude in pregnant women in the intervention and control groups before and after sexual counseling

\begin{tabular}{lllll}
\hline Group & $\begin{array}{l}\text { Before counseling } \\
(\text { mean } \pm \text { SD) }\end{array}$ & $\begin{array}{l}\text { After counseling } \\
(\text { mean } \pm \text { SD) }\end{array}$ & $\begin{array}{l}\text { Changes } \\
(\text { mean } \pm \text { SD) }\end{array}$ & $\begin{array}{l}\text { Paired } t \text {-test } \\
\text { Intervention }\end{array}$ \\
Control & $23.96 \pm 8.53$ & $35.62 \pm 6.01$ & $11.66 \pm 5.10$ & $P=0.0001$ \\
Student's $t$-test & $23.62 \pm 7.03$ & $23.20 \pm 5.69$ & $0.42 \pm 3.03$ & $P=0.3$ \\
\hline
\end{tabular}

Abbreviation: NA, not applicable.

during pregnancy could help to increase pregnant women's satisfaction.

Since the training program for the intervention group highlighted the anatomy and physiology of male and female reproductive organs, sexual activity during pregnancy, and common beliefs about sexual issues, it mostly affected the pregnant women's viewpoints on the traditional perceptions such as damage to the fetus, maternal infections, and pains. Perhaps, the given training plans did not contain sufficient information with regard to the role of cultural and religious virtues about sexual activity influencing traditional perceptions such as sexual perversions. For this reason, an increased mean score was not perceptible; so, further studies are needed to address the impact of such consultation.

The results further showed that the mean score of sexual attitude in the intervention group was notably greater than in the control group after sexual counseling, and the ANCOVA test indicated that sexual counseling resulted in a more appropriate attitude toward sexual activity during pregnancy. Hence, the greatest changes in scores were related to unfavorable attitudes of decreasing sexual activity and pleasure for reasons such as physical changes, lack of having sexual pleasure without intercourse, and having low sexual attractiveness, and the least changes were related to a decrease in attention from the husband during pregnancy and having sex with a fear of aggression from him. In line with this finding, the study by Bayrami et $\mathrm{al}^{24}$ shows that couples avoid having sex during pregnancy due to problems such as abdominal distention. The studies by Pauleta et $\mathrm{al}^{27}$ and Jamali and Mosalanejad ${ }^{28}$ also indicate that pregnant women found that their sexual pleasure declined in comparison with the prepregnancy period.

In the current paper, consultation conducted on the manner of sexual activity during pregnancy and alternative methods of expressing intimacy caused a change in unpleasant attitudes; however, because of cultural limits regarding sex consultation for male partners, it could not influence attitudes such as a decline in attention from male partners to pregnant women and a fear of aggression by their husbands. Therefore, an increased mean score was not recognizable for both partners. In further studies, male partners should participate in sexual counseling classes to increase the effectiveness of sexual education.

At the start of the study, traditional perceptions about sexual issues were common in the pregnant women, but after participating in group sexual counseling sessions, a significant change took place. The most common traditional perceptions (sexual activity leading to damage to the fetus, abdominal pain, excruciating genital pain, infection in the mother, and abortion) were significantly decreased in the intervention group compared with the pretest and the control group. ANCOVA analysis indicated that sexual counseling reduced the sexual traditional perceptions of the women in the intervention group and that the impact of counseling was stable 6 weeks after its completion. The results of the present study are consistent with the findings of Sossah ${ }^{17}$ and Eryilmaz et $\mathrm{al}^{29}$ in which the reasons for reduced frequency of intercourse in pregnancy were related to fatigue, fear of injury to the fetus, fear of miscarriage, and preterm labor induction. Also, the separate studies by Rahimi and Seyyed ${ }^{30}$ in Tabriz, Nematollahzade et $\mathrm{al}^{31}$ in Tehran, Bayrami et $\mathrm{al}^{24}$ in Tabriz, Pasha et $\mathrm{al}^{20}$ in Babol, Shojae et $\mathrm{al}^{26}$ in Gorgan, and Riazi et $\mathrm{al}^{6}$ in Hamedan reported fear of injury to the fetus, fear of premature delivery, and fear of infection in more than half of the pregnant women, which is consistent with the findings of the current study.

The results showed that there was initially a considerable number of negative attitudes toward sexual issues in pregnant women, but after participating in the group sexual counseling sessions, a significant positive change took place. This means that some attitudes (such as feelings of reduced sexual attractiveness, reduced frequency of sex because of body changes due to pregnancy, and having unpleasant feelings toward sex during pregnancy) were significantly reduced in the intervention group compared with their pretest scores and also the control group. ANCOVA results indicated that sexual counseling improved attitudes toward sexuality of the women in the intervention group and that the impact of counseling was stable 6 weeks postintervention. In this regard, studies by Pauleta et al, ${ }^{27}$ Merghati Khoei et $\mathrm{al}^{25}$ in Tabriz, 
Sattarzadeh et $\mathrm{al}^{32}$ in Tabriz, and Jamali and Mosalanejad ${ }^{28}$ revealed that pregnant women reported a decrease in their sexual attraction compared to before pregnancy. Since a pregnant women's concern about their reduced sexual attraction can lead to sexual problems, it is necessary for health care professionals to offer consultations to correct negative perceptions about physical changes of the body during pregnancy.

Our findings indicated that only a few pregnant women had received information about sexual issues from health care employees. Based on the results of the studies by Uwapusitanon and Choobun ${ }^{33}$ (in Thailand) and Fok et al, ${ }^{34} 22 \%$ and $20 \%$ of pregnant women, respectively, had received information about sexual relations in pregnancy from their doctor. In a study conducted in Nigeria, $79.5 \%$ of the study participants expressed a need for consultation about their sexuality during pregnancy. The study by Riazi et $\mathrm{al}^{6}$ in Hamedan showed that $86.7 \%$ of pregnant women did not question health care providers about sexual activity during pregnancy. Since sexual relations are the most private marital issue and also due to cultural and religious restrictions in our society, it is probable that people are not able to talk comfortably about sexual issues; therefore, it is recommended that sexual training and counseling be a part of pregnancy care in Iran.

Ozgoli et al ${ }^{35}$ concluded that people with negative attitudes toward sexual relations during pregnancy accept information from resources that cause more negative attitudes, stress, and fear due to the limited knowledge of pregnant women. Thus, the importance of correcting their attitude and increasing their awareness is obvious, and long-term training programs on sexual health are necessary. ${ }^{35}$

In explaining the obtained results, it can be summarized that misconceptions and negative attitudes during pregnancy showed a significant reduction 6 weeks after counseling in the intervention group compared with the control group. This confirmed the positive role of training and consultation in correcting the general beliefs of pregnant women toward sexual relations during this period. In the study by Rafaei Shirpak et al, ${ }^{36}$ educational intervention caused a significant increase in the knowledge and attitude of married women referred to health centers for sexual issues. Furthermore, this intervention created significant changes concerning the intention to change the behavior and in some of the studied behaviors. These researchers believe that after considering the legal and administrative limitations, cultural and religious sensitivities, and knowing the health system, an effective program for the promotion of sexual health education can be designed and implemented. The study by Afshar et $\mathrm{al}^{22}$ in Tabriz also shows that educational intervention leads to an improvement of sexual function in pregnant women. Our results are further consistent with the results of the studies by Kilmann et al, ${ }^{37}$ Sehat et al, ${ }^{38}$ and Karimi et $\mathrm{a}^{39}$ that confirm the effectiveness of sexual education. However, a study by Wannakosit and Phupong ${ }^{40}$ in Thailand showed no significant difference between the two groups of intervention and control after training regarding the sexual behavior. This difference between our study and the study by Wannakosit and Phupong ${ }^{40}$ may be due to demographic characteristics, cultural differences, and educational tools or techniques (the number of group counseling sessions in our study was five sessions, each of 90 minutes, compared to 20 minutes long sessions of the cited study). Furthermore, we used a training package and training compact disc with simple language.

With regard to the different sociocultural and religious background of the women in the studied region of the country, a generalization of these results to other women should be made with caution. The relatively small sample size and difficulty in honest expression of sexual attitudes, beliefs, and behaviors are among the other limitations of the current study.

\section{Conclusion}

In light of the positive effect of group sexual counseling on improving the attitude of pregnant women about sexual issues and reducing sexual traditional perceptions in pregnancy, it is recommended that this educational intervention be integrated into prenatal consultations and care. This may lead to satisfying and improving the sexual needs of couples, reducing stress, and also increasing support from the spouse by helping to improve the quality of life and the dimensions of marital relationships of pregnant women during this critical period of their lives.

\section{Acknowledgments}

The authors thank and appreciate all the pregnant women who participated in the study, as well as the health care workers of the health departments of Zahedan University of Medical Sciences. This study was derived from the MSc thesis consultation in Midwifery in the School of Nursing and Midwifery of Zahedan with the number IR.ZAUMS.REC.1394.103. We also thank the deputy director of Research and Technology of Zahedan University of Medical Sciences.

\section{Author contributions}

All authors contributed substantially to the study design, data gathering, statistical analyses, and interpretation of the 
data. All authors critically revised, reviewed, and edited the manuscript and have seen and approved the final draft.

\section{Disclosure}

The authors report no conflicts of interest in this work.

\section{References}

1. Sagiv-Reiss DM, Birnbaum GE, Safir MP. Changes in sexual experiences and relationship quality during pregnancy. Arch Sex Behav. 2012; 41(5):1241-1251.

2. Isajeva J, Šilkūnas M, Drąsutienė GS, Bartkevičienè D. Features of the sexual life during pregnancy. Acta Med Litu. 2012;19(2):67-74.

3. Hanafy S, Srour NE, Mostafa T. Female sexual dysfunction across the three pregnancy trimesters: an Egyptian study. Sex Health. 2014; 11(3):240-243.

4. Efe H, Bozkurt M, Sahin L, Mutlu MF, Api M, Çetin A. The effects of pregnancy on the sexual life of Turkish women. Proc Obstet Gynecol. 2014;4(1):1-11.

5. Gazafroodi KA, Najafi F, Kazemnejad E, Rahimikian F, Shariat M, Rahnama P. Comparison of sexual function between nulliparous with multiparous pregnant women. Hayat. 2012;18(5):55-63.

6. Riazi H, Banoozadeh S, Moghimbigi A, Amini L. The effect of sexual health education on sexual function during pregnancy. Payesh. 2013; $1(2): 7-12$.

7. Serati M, Salvatore S, Siesto G, et al. Female sexual function during pregnancy and after childbirth. J Sex Med. 2010;7(8):2782-2790.

8. Santiago LRS, da Silva Lara LA, Salata Rom A, Mata Tiezzi M, de Sá Rosa e Silva A. Impact of pregnancy on the sex life of women: state of the art. Int J Clin Med. 2013;4(5):257-264.

9. Liu HL, Hsu P, Chen KH. Sexual activity during pregnancy in Taiwan: a qualitative study. Sex Med. 2013;1(2):54-61.

10. Bello FA, Olayemi O, Aimakhu CO, Adekunle AO. Effect of pregnancy and childbirth on sexuality of women in Ibadan, Nigeria. ISRN Obstet Gynecol. 2010;2011:856586.

11. Murtagh J. Female sexual function, dysfunction, and pregnancy: implications for practice. J Midwifery Womens Health. 2010;55(5):438-446.

12. Polomeno V. Sex and pregnancy: a perinatal educator's guide. J Perinat Educ. 2000;9(4):15.

13. Brown HL, McDaniel ML. A review of the implications and impact of pregnancy on sexual function. Curr Sex Health Rep. 2008;5(1): $51-55$.

14. Ahmadi Z, Janmohammadi S. Factors influencing the sexual satisfaction of Iranian primigravid women. J Client Centered Nurs Care. 2015; 1(1):4-9.

15. Heydari M. Couples' knowledge and attitude about sexuality in pregnancy. Tehran Univ Med J. 2006;64(9):83-89.

16. Heydari M, Mohammadi Kh, Faghihzadeh S. The study of sexuality changes during pregnancy. Bimonth J Med Daneshvar. 2005;13(61):27-32.

17. Sossah L. Sexual behavior during pregnancy: a descriptive correlational study among pregnant women. Eur J Res Med Sci. 2014;2(1):16-27.

18. Senkumwong N, Chaovisitsaree S, Rugpao S, Chandrawongse W, Yanunto $\mathrm{S}$. The changes of sexuality in Thai women during pregnancy. J Med Assoc Thai. 2006;89(4):S124-S129.

19. Read J. ABC of sexual health: sexual problems associated with infertility, pregnancy, and ageing. BMJ. 2004;329(7465):559-561.

20. Pasha H, Hadj Ahmadi M. Evaluation of sexual behaviors in pregnant women and some related factors. Bimonth J Hormozgan Univ Med Sci. 2007;10(4):343-348.
21. Berek J. Berek \& Novak's Gynecology. 14th ed. Philadelphia, PA: Lippincott Williams \& Wilkins; 2007:314.

22. Afshar M, Mohammad-Alizadeh-Charandabi S, Merghti-Khoei ES, Yavarikia P. The effect of sex education on the sexual function of women in the first half of pregnancy: a randomized controlled trial. J Caring Sci. 2012;1(4):173-181.

23. Bayrami R, Sattarzadeh N, Koochaksariie FR, Pezeshki MZ. Sexual dysfunction in couples and its related factors during pregnancy.J Reprod Infertil. 2008;9(3):271-282.

24. Bayrami R, Sattarzadeh N, Koocheksarai FR, Pezeshki M. Evaluation of sexual behaviors and some of its related factors in pregnant women, Tabriz, Iran 2005. Urmia Med J. 2009;20(1):1-7.

25. Merghati Khoei E, Afshar M, Yavarikia P, Mohammad-AlizadehCharandabi S. Beliefs and sexual behavior in women referred to health centers in the city of Karaj. Iran J Obstet Gynecol Infertil. 2011;15(9): $7-14$.

26. Shojae M, Jouybari L, Sanagoo A. The sexual activity during pregnancy among a group of Iranian women. Arch Gynecol Obstet. 2009;279(3): 353-356.

27. Pauleta JR, Pereira NM, Graça LM. Sexuality during pregnancy. J Sex Med. 2010;7(1 Pt 1):136-142.

28. Jamali S, Mosalanejad L. Sexual dysfunction in Iranian pregnant women. Iran J Reprod Med. 2013;11(6):479-486.

29. Eryilmaz G, Ege E, Zincir H. Factors affecting sexual life during pregnancy in eastern Turkey. Gynecol Obstet Invest. 2004;57(2): 103-108.

30. Rahimi S, Seyyed RE. Sexual behavior during pregnancy: a descriptive study of pregnant women in Tabriz, Iran. J Kerman Univ Med Sci. 2004;3(4):291-299.

31. Nematollahzade M, Maasoumi R, Lamyian M. Study of women's attitude and sexual function during pregnancy. J Ardabil Univ Med Sci. 2010;10(3):241-249.

32. Sattarzadeh N, RanjbarKoochaksaraiie F, Pezeshki MZ, Bayrami R. Sexual experiences of pregnant women referred to health centers of Tabriz. Iran J Nurs Midwifery Res. 2005;3:46-55.

33. Uwapusitanon W, Choobun T. Sexuality and sexual activity in pregnancy. J Med Assoc Thai. 2004;87:45-49.

34. Fok WY, Chan LYS, Yuen PM. Sexual behavior and activity in Chinese pregnant women. Acta Obstet Gynecol Scand. 2005;84(10):934-938.

35. Ozgoli G, Dolatian M, Ozgoli M, Khoushabi K. Changing sexual interest during pregnancy in woman referring to primary health care centers in Shahid Beheshti University of Medical Sciences. J Nurs Midwifery Shahid Beheshti Univ Med Sci. 2008;18(61):137-147.

36. Rafaei Shirpak K, Chinichian M, Eftekhar Ardabili H, Pourreza AG, Ramezan Khani A. Need assessment: sexual health education in family planning centers, Tehran, Iran. Payesh. 2010;9(3):251-260.

37. Kilmann PR, Mills KH, Bella B, et al. The effects of sex education on women with secondary orgasmic dysfunction. J Sex Marital Ther. 1983; 9(1):79-87.

38. Sehat F, Sehat N, Shahsiah M, Mohebi S, Tabaraie Y. The effect of sex education on sexual satisfaction increase of couples' in Esfahan. Life Sci J. 2013;10(5):31-35.

39. Karimi A, Dadgar S, Afiat M, Rahimi N. The effect of sexual health education on sexual satisfaction in couples. Iran J Obstet Gynecol Infertil. 2013;15(42):22-30.

40. Wannakosit S, Phupong V. Sexual behavior in pregnancy: comparing between sexual education group and nonsexual education group. J Sex Med. 2010;7(10):3434-3438. 


\section{Supplementary materials}

\begin{tabular}{|c|c|c|c|}
\hline Row & Perceptions of sexual relations during pregnancy & Yes & No \\
\hline I & Sexual activity causes infections in a pregnant mother & & \\
\hline 2 & Sexual activity causes premature birth & & \\
\hline 3 & Sexual activity causes tearing & & \\
\hline 4 & Sexual activity causes severe vaginal pains & & \\
\hline 5 & Sexual activity causes bleeding & & \\
\hline 6 & Sexual activity causes stomachache, weakness, backache, nausea, fatigue, and other physical symptoms & & \\
\hline 7 & Sexual activity damages the fetus & & \\
\hline 8 & Sexual activity causes spontaneous abortion & & \\
\hline 9 & Sexual activity causes the fetus to lose its virginity & & \\
\hline 10 & Sexual activity causes contaminating the fetus with semen & & \\
\hline II & The fetus can perceive when sexual activity occurs & & \\
\hline 12 & High sexual activity during pregnancy will increase sexual deviation in the child after birth & & \\
\hline 13 & Have applied training interventions been effective to you? & & \\
\hline
\end{tabular}

Figure SI Questionnaire of sexual perceptions in pregnant women.

\begin{tabular}{|c|c|c|c|c|c|c|}
\hline Row & Item & Agree & $\begin{array}{l}\text { Agree } \\
\text { somewhat }\end{array}$ & $\begin{array}{l}\text { Neither } \\
\text { agree/ } \\
\text { disagree }\end{array}$ & $\begin{array}{l}\text { Disagree } \\
\text { somewhat }\end{array}$ & Disagree \\
\hline 1 & Sexual pleasure is not feasible without intercourse & & & & & \\
\hline 2 & Sexual relations need to stop during pregnancy for the sake of fetus health & & & & & \\
\hline 3 & Pregnant women are less sexually attractive & & & & & \\
\hline 4 & Having sexual relations during pregnancy is unpleasant & & & & & \\
\hline 5 & $\begin{array}{l}\text { Physical changes resulting from pregnancy lead to decline in sexual } \\
\text { activity and pleasure }\end{array}$ & & & & & \\
\hline 6 & Male partners pay less attention to pregnant women & & & & & \\
\hline 7 & Pregnancy is a latency period for sexual activity & & & & & \\
\hline 8 & Sexual excitement is dangerous for the mother and her fetus & & & & & \\
\hline 9 & Having sex is not recommended ethically if the fetus is female & & & & & \\
\hline 10 & $\begin{array}{l}\text { Culturally, sexual activity during pregnancy without intercourse has no } \\
\text { meaning }\end{array}$ & & & & & \\
\hline II & Pregnant women have to have sex to avoid aggression from their partners & & & & & \\
\hline 12 & Any sexual relation is a sin during pregnancy & & & & & \\
\hline
\end{tabular}

Figure S2 Questionnaire of attitudes toward sexual activity during pregnancy.

International Journal of Women's Health

\section{Publish your work in this journal}

The International Journal of Women's Health is an international, peerreviewed open-access journal publishing original research, reports, editorials, reviews and commentaries on all aspects of women's healthcare including gynecology, obstetrics, and breast cancer. The manuscript management system is completely online and includes
Dovepress

a very quick and fair peer-review system, which is all easy to use. Visit http://www.dovepress.com/testimonials.php to read real quotes from published authors.

\footnotetext{
Submit your manuscript here: http://www.dovepress.com/international-journal-of-womens-health-journal
} 